\title{
Effects of 1, 25-Dihydroxyvitamin D3 on Experimental Autoimmune Myocarditis in Mice
}

\author{
Fen Hua Lianhua Yana Shuai Lu ${ }^{a}$ Wenhan Maa Ya Wang ${ }^{a}$ Yuzhen Weia \\ Xiaofei Yan ${ }^{a}$ Xin Zhao ${ }^{a}$ Zhijian Chen ${ }^{a}$ Zhaohui Wang ${ }^{a}$ Bo Cheng ${ }^{b}$ \\ aLaboratory of Cardiovascular Immunology, Institute of Cardiology, Union Hospital, Tongji Medical \\ College, Huazhong University of Science and Technology, Wuhan, 'bepartment of Stomatology, Union \\ Hospital, Tongji Medical College, Huazhong University of Science and Technology, Wuhan, China
}

\section{Key Words}

Experimental autoimmune myocarditis $・ 1,25(\mathrm{OH}) 2 \mathrm{D} 3 \cdot$ Apoptosis • Autophagy

\begin{abstract}
Background/Aims: Myocarditis is an important inflammatory disease of the heart which causes life-threatening conditions. 1, 25(OH)2 D3 has effects on multiple systems and diseases. The present study was aimed to investigate the effect of $1,25(\mathrm{OH}) 2$ D3 on experimental autoimmune myocarditis (EAM), and explored the underlying mechanisms involved. Methods: EAM was induced by immunizing BALB/c mice with cardiac $\alpha$-myosin heavy chain peptides (MyHC- $\alpha) .1,25(\mathrm{OH}) 2$ D3 $(1,000 \mathrm{ng} / \mathrm{kg}$ once) or vehicle was administered intraperitoneally every other day during the entire experiment. On day 21 , transthoracic echocardiography was performed and cardiac inflammatory infiltration was detected by hematoxylin and eosin (HE). The terminal deoxynucleotidyl transferase mediated dUTP nick-end labeling (TUNEL) assay, and Western blots for the expression of protein caspase-3 and cleaved-caspase3 were used to evaluate apoptosis. Transmission electron microscopy and Western blots for the expression of protein Beclin-1, LC3B, and P62 were used to evaluate autophagy. Results: The ratio of heart weight/body weight was significantly reduced in 1, 25(OH)2 D3 -treated EAM mice, compared with vehicle -treated ones. 1, 25(OH)2 D3 treatment improved cardiac function, diminished cell infiltration in cardiac, suppressed myocardial apoptosis, decreased the number of autophagosomes, and decreased the protein expression of Beclin-1, LC3-II and p62. Conclusions: The present results demonstrated that administration of $1,25(\mathrm{OH}) 2$ D3 decreased EAM severity. 1, 25(OH)2 D3 treatment may be a feasible therapeutic approach for EAM.
\end{abstract}




\section{Cellular Physiology Cell Physiol Biochem 2016;38:2219-2229 \\ \begin{tabular}{ll|l} 
and Biochemistry & $\begin{array}{l}\text { DOI: 10.1159/000445577 } \\
\text { Published online: May 17, } 2016\end{array}$ & $\begin{array}{l}\text { () 2016 The Author(s). Published by S. Karger AG, Basel } \\
\text { www.karger.com/cpb }\end{array}$ \\
\cline { 1 - 2 }
\end{tabular} \\ Hu et al.: 1, 25(OH)2 D3 on Autoimmune Myocarditis}

\section{Introduction}

Myocarditis, defined as inflammation of the heart with severe ventricular dysfunction, is a major cause of dilated cardiomyopathy and heart failure in individuals younger than 40 years old, which often leads to life-threatening arrhythmia and cardiac sudden death [1]. The pathogenesis of myocarditis remains undefined. Elevated circulating autoantibodies are commonly found in patients with myocarditis or dilated cardiomyopathy, and autoantibody removal improves cardiac function [2,3]. Autoimmunity is considered to play an important role in the pathogenesis of myocarditis, and cardiac myosin is one of the main autoantigens in virus-induced myocarditis in mice [4]. Many attempts have been made to find potential therapeutic targets for myocarditis, but no specific and effective treatment strategy has been established $[1,5]$.

Autophagy, a conserved intracellular bulk degradation mechanism, is an adaptive response to harsh conditions, allowing cells to recycle damaged organelles and misfolded cellular proteins. The core of this process is the formation of autophagosomes. Autophagosomes, which have a double membrane, have nonselective cytoplasmic components, such as mitochondria and peroxisomes that are often transported to the lysosome/vacuole for degradation [6]. Autophagy can be induced under various stresses, such as starvation and infection, and it can provide nutrients and energy under starvation conditions [7]. Modest autophagy plays an important role in maintaining general homeostasis and participating in various physiological and pathological conditions, such as cell development, cancer, and pathogenic infections [8-10].

Vitamin D is a fat-soluble secosteroid hormone that is obtained from dietary sources or from endogenous production in the skin following exposure to adequate sunlight [11]. 1, 25-Dihydroxyvitamin D3 $(1,25(\mathrm{OH}) 2 \mathrm{D} 3)$ is the active form of vitamin D. It exerts its effects by binding to the vitamin D receptor (VDR), which is a ligand-modulated nuclear receptor transcription factor $[12,13] .1,25(\mathrm{OH}) 2 \mathrm{D} 3$ has high receptor affinity and mediates most biological effects of vitamin D. It exerts pleiotropic effects on multiple systems and diseases, including calcium and bone homeostasis, the regulation of innate and adaptive immune responses, and the modulation of cancer growth and development, cell proliferation, apoptosis, and many chronic disorders $[12,14]$.

Vitamin D deficiency is associated with increased risk of colon, lung, ovarian, prostate, bladder and breast cancer, and poor prognosis of hematological malignancies [15-18]. Low vitamin D levels are associated with increased incidence of autoimmune disorders, such as systemic lupus erythematosus (SLE), multiple sclerosis (MS), rheumatoid arthritis (RA) and type 1 diabetes [19].

EAM is an animal model for human acute myocarditis. Based on the above findings, in this study, we aimed to investigate the effect of 1, 25(OH)2 D3 on an EAM mouse model.

\section{Materials and Methods}

\section{Animals}

Male BALB/c mice aged 6 - 8 weeks old were purchased from the Experimental Animal Center of Wuhan University (Hubei province, China). All of the animals were housed in a specific pathogen-free mouse room in the experimental animal center of Tongji Medical College. They had free access to standard rodent chow and water. All experimental procedures were performed according to the Guide for the Care and Use of Laboratory Animals published by the US National Institutes of Health (NIH publication No.85-23, Revised 1996) and were approved by the Animal Care and Use Committee of Union Hospital, Tongji Medical College, Huazhong University of Science and Technology.

Induction of EAM and groups

Eight-week-old male BALB/c mice were subcutaneously injected with cardiac $\alpha$-myosin heavy chain peptides (MyHC- $\alpha$, sequence: acetyl-SLKLMATLFSTYAS; purity > 95\%; GL Biochem, Shanghai, China), 


\section{Cellular Physiology Cell Physiol Biochem 2016;38:2219-2229 \begin{tabular}{ll|l} 
and Biochemistry $10.1159 / 000445577$ & Published online: May 17, 2016 & $\begin{array}{l}\text { ( ) 2016 The Author(s). Published by S. Karger AG, Basel } \\
\text { www.karger.com/cpb }\end{array}$ \\
\hline
\end{tabular} \\ Hu et al.: 1, 25(OH)2 D3 on Autoimmune Myocarditis}

dissolved in phosphate-buffered saline (PBS) $(2 \mathrm{mg} / \mathrm{ml})$, and emulsified 1:1 with complete Freund's adjuvant (CFA; Sigma-Aldrich, America). Each mouse was subcutaneously injected with $200 \mu$ l of emulsion (containing $200 \mu \mathrm{g}$ of MyHC- $\alpha$ peptide) on days 0 and 7 to induce EAM [20]. BALB/c mice were randomly divided into the following three groups: normal control (control group, $n=10$ ), EAM+ vehicle (EAM group, $\mathrm{n}=10)$, and $\mathrm{EAM}+1,25(\mathrm{OH}) 2 \mathrm{D} 3(1,25(\mathrm{OH}) 2 \mathrm{D} 3$ group, $\mathrm{n}=10)$. The control group mice were treated with complete Freund's adjuvant mixed with PBS. The EAM+1, 25(OH)2 D3 group was treated with MyHC- $\alpha$ and 1, 25(OH)2 D3. 1, 25(OH)2 D3 (Sigma Chemical, America) was dissolved in 95\% ethyl alcohol solution prepared for stock solution and diluted in peanut oil for intraperitoneal injection. The dosage of $1,25(\mathrm{OH}) 2$ D3 was $1,000 \mathrm{ng} / \mathrm{kg}$ in a single injection. The injection was administered every other day throughout the entire experiment, and the first injection was given on the day 0 . The EAM+vehicle group was treated with MyHC- $\alpha$ and vehicle, and the mice received vehicle injections according to the same schedule as that used for the EAM+1, 25(OH)2 D3 group. The assessment and analysis of acute EAM was conducted on day 21. No mice died during the experiments.

\section{Echocardiography}

On day 21, mice were anesthetized with $1.5 \%$ isoflurane, and transthoracic echocardiography was performed using a Vevo 1100 Imaging System (VisualSonics, Toronto, Canada) equipped with a 30-MHz transducer (M-mode) according to the methods described in previous reports [4]. Left ventricular internal dimensions at end-systole and end-diastole (LVEDs and LVEDd) were measured. Three consecutive cycles were measured for each assessment, and the average values were recorded. The left ventricular ejection fraction (LVEF) and left ventricular fractional shortening (LVFS) were then calculated. All echocardiography assessments were performed by the same investigator who was blinded to the treatments.

\section{Tissue harvesting and histopathology}

The mice were weighed and euthanized, and the chests were then opened. The hearts were removed and immediately placed in ice-cold PBS. The hearts were weighed, and the ratio of heart weight to body weight (HW/BW) was calculated. Ventricular tissues were fixed in 4\% paraformaldehyde and embedded in paraffin. Then, 5- $\mu \mathrm{m}$ sections were cut transversely and stained with hematoxylin and eosin (H\&E). The severity of myocarditis was assessed based on the infiltrated area ratio, which was the percentage of the heart section with inflammatory infiltrates compared with the whole transverse heart section, and the histological pathological scoring system was as follows: grade 0, no infiltration; grade 1, infiltrated area ratio less than $25 \%$; grade 2 , infiltration area of $25 \%$ to $50 \%$; grade 3 , infiltration area of $50 \%$ to $75 \%$; and grade 4 , infiltration area more than $75 \%[21,22]$. Five sections from each heart were scored by two independent researchers who were blinded to the treatments.

\section{TUNEL assay}

Apoptotic cells in the myocardium were identified by terminal deoxynucleotidyl transferase mediated dUTP nick-end labeling (TUNEL) according to the manufacturer's instructions (Roche Diagnostics, Germany). Apoptotic nuclei were detected by green fluorescein staining, total nuclei were identified by DAPI labeling (blue), and cardiomyocytes were identified by anti- $\alpha$-actin antibody staining (red).

\section{Transmission electron microscopy}

Autophagosomes were detected as previously described [23]. Briefly, heart tissues were fixed in 3\% glutaraldehyde for $24 \mathrm{~h}$ and $1 \%$ osmium tetroxide for $2 \mathrm{~h}$. The ultrathin sections were stained with uranyl acetate and lead citrate. Random sections were assessed by an electron microscopy technician who was blinded to the treatments. For each section, 20 electron micrographs were obtained with magnifications of 1,700 and $3,500 \mathrm{x}$.

\section{Western blot analysis}

Total proteins in the heart tissues were prepared using standard protocols, and the protein concentrations in the lysates were determined with a BCA Protein Assay Kit (Thermo Scientific). Equal amounts of protein ( $80 \mu \mathrm{g} / \mathrm{lane}$ ) were separated on $12 \%$ sodium dodecyl sulfate-polyacrylamide gel electrophoresis (SDS-PAGE) gels and transferred onto polyvinylidene fluoride (PVDF) membranes. The membranes were blocked in Tris-buffered saline with Tween 20 (TBST) containing 5\% skim milk for 2 


\section{Cellular Physiology Cell Physiol Biochem 2016;38:2219-2229 \begin{tabular}{lll} 
and Biochemistry Puil 10.1159/000445577 & $\begin{array}{l}\text { O 2016 The Author(s). Published by S. Karger AG, Basel } \\
\text { www.karger.com/cpb }\end{array}$ \\
\cline { 2 - 3 }
\end{tabular} \\ Hu et al.: 1, 25(OH)2 D3 on Autoimmune Myocarditis}

$\mathrm{h}$ at room temperature, and they were then incubated with primary antibodies against Beclin-1 (1:1,000, CST), LC3B (1:500, CST), caspase 3 (1:1,000, CST), GAPDH (1:3,000, CST), and P62(SQSTM1/sequestome 1) $(1: 1,000, \mathrm{CST})$ at $4^{\circ} \mathrm{C}$ overnight, followed by washing with TBST. The samples were then incubated with corresponding HRP-conjugated secondary antibodies (1:4,000, Antgene Biotechnology, China) for $2 \mathrm{~h}$ at room temperature. The expression levels of target protein bands were detected using enhanced chemiluminescence (Millipore) and were quantified by densitometry with the BioRad image analysis program Image Lab Software.

\section{Statistical analysis}

Data are presented as the means \pm SEMs and were analyzed using SPSS 18.0 for Windows. Statistical analysis was performed with one-way analysis of variance (ANOVA) when appropriate. Western blot densities were analyzed with the Kruskal-Wallis test followed by Dunn's post hoc test. $\mathrm{P}<0.05$ was considered statistically significant.

\section{Results}

\section{1, 25(OH)2 D3 improved cardiac function of EAM mice}

As shown in Fig. 1A-E, the LVEF and LVFS were significantly reduced in the EAM group compared with the normal control group (LVEF 73.40\% $\pm 0.96 \%$ and LVFS $41.10 \% \pm 0.76 \%$ in the normal control group vs. LVEF $47.05 \% \pm 1.77 \%$ and LVFS $23.25 \% \pm 1.1 \%$ in the EAM group, $\mathrm{P}<0.01)$. Compared with the EAM group, 1, 25(OH)2 D3 treatment improved LVEF $(62.71 \% \pm 1.68 \%$ vs. $47.05 \% \pm 1.77 \%, \mathrm{P}<0.01)$ and LVFS $(32.98 \pm 1.14 \%$ vs. $23.25 \pm 1.1 \%$, $\mathrm{P}<0.01$ ). Similarly, LVEDd and LVEDs were increased in the EAM group compared with the normal control group (LVEDd $3.16 \pm 0.26$ in the normal control group vs. LVEDd $3.94 \pm 0.14$

Fig. 1. Echocardiographic analyses. Mice were induced with EAM, and they were treated with $1,25(\mathrm{OH})_{2}$ D3 (VitD3) or vehicle. Cardiac function was determined by echocardiography on day 21. (A) Representative images of M-mode echocardiograms; (B) LVEF(\%); (C) LVFS (\%); (D) LVEDd (mm); (E) LVEDs $(\mathrm{mm})$. Values are expressed as the means \pm SEMs, $\mathrm{n}=6$ animals per group. ${ }^{*} \mathrm{P}<0.05$ or ${ }^{* *} \mathrm{P}<0.01$ vs. the control group; ${ }^{\mathrm{P}}<0.05$ or ${ }^{\# \# \mathrm{P}<0.01}$ vs. the EAM group. VitD3 treatment significantly prevented the progression of left ventricular dysfunction.

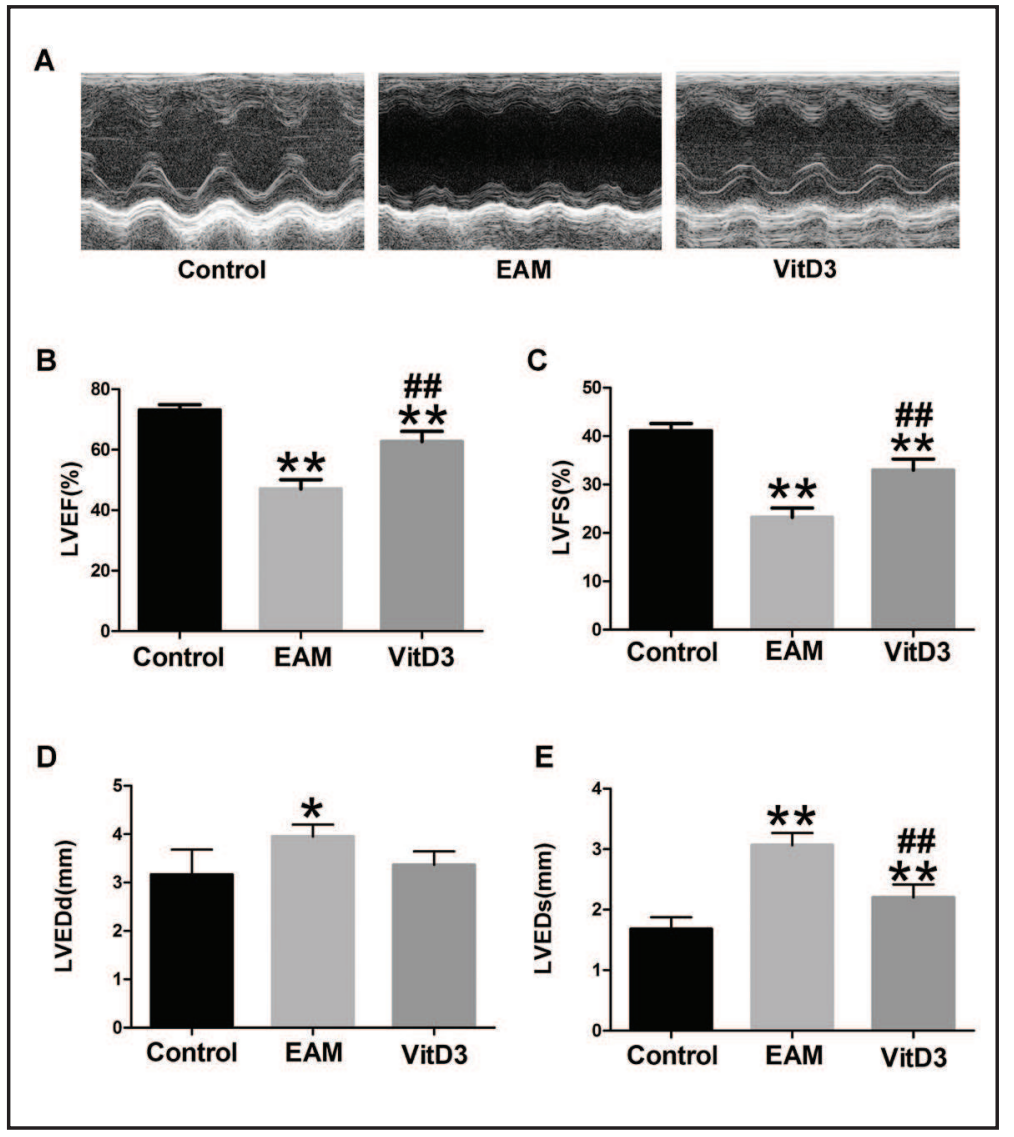




\section{Cellular Physiology Cell Physiol Biochem 2016;38:2219-2229 \begin{tabular}{ll|l} 
aOI: 10.1159/000445577 & $\begin{array}{l}\text { @ 2016 The Author(s). Published by S. Karger AG, Basel } \\
\text { www.karger.com/cpb }\end{array}$ \\
\hline
\end{tabular}

A

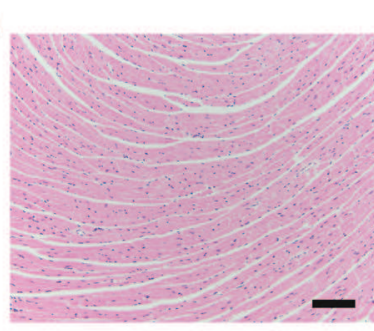

Control

B

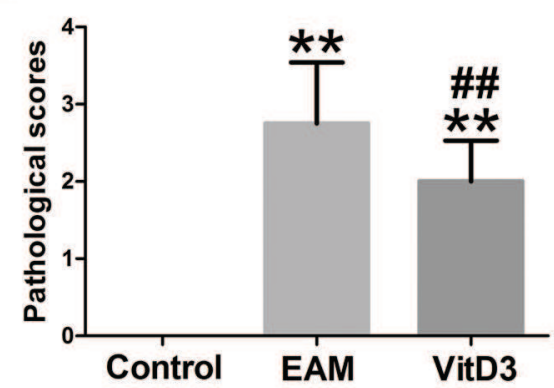

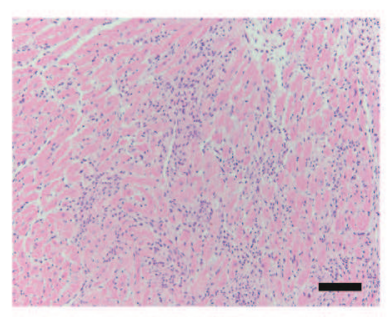

EAM

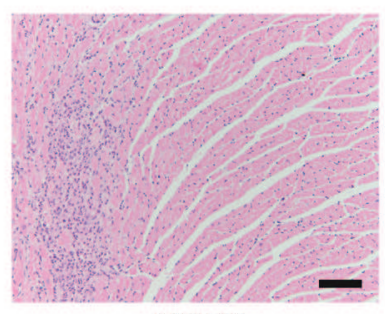

VitD3

\section{C}

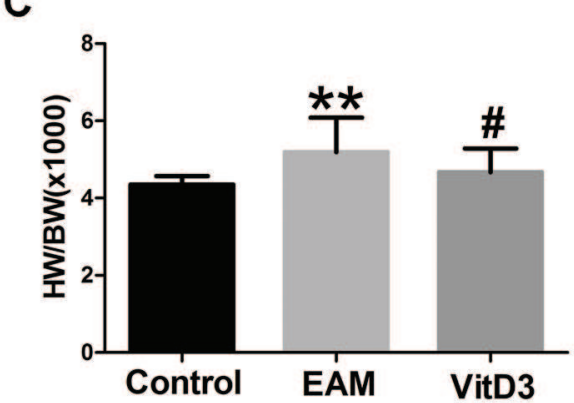

Fig. 2. Inflammatory infiltration was reduced by $1,25(\mathrm{OH})_{2}$ D3 treatment. Heart tissue sections were stained with hematoxylin and eosin (H\&E) to evaluate inflammation. (A) Representative images of tissues stained with H\&E (magnification $\times 200$ ), Scale bar $=100 \mu \mathrm{m}$; (B) The pathological scores of heart sections; (C) The ratios of HW/BW. Values are expressed as the means \pm SEMs, $\mathrm{n}=10$ animals per group. $* \mathrm{P}<0.05$ or ${ }^{* *} \mathrm{P}<0.01$ vs. the control group; ${ }^{\mathrm{P}}<0.05$ or ${ }^{\# \#} \mathrm{P}<0.01$ vs. the EAM group.

in the EAM group, $\mathrm{P}<0.05$; LVEDs $1.68 \pm 0.1$ in the normal control group vs. LVEDs 3.06 \pm 0.1 in the EAM group, $\mathrm{P}<0.01)$. Compared with the EAM group, LVEDd and LVEDs were decreased in the 1, 25(OH)2 D3 group (LVEDd $3.45 \pm 0.14$ in the 1, 25(OH)2 D3 group vs. LVEDd $3.94 \pm 0.14$ in the EAM group, $\mathrm{P}=0.082$; LVEDs $2.20 \pm 0.11$ in the $1,25(\mathrm{OH}) 2 \mathrm{D} 3$ group vs. LVEDs $3.06 \pm 0.1$ in the EAM group, $\mathrm{P}<0.01$ ).

Together, these results showed that left ventricular dysfunction occurred in EAM mice and that $1,25(\mathrm{OH}) 2$ D3 played a role in improving cardiac function in EAM mice.

\section{1, 25(OH)2 D3 reduced inflammatory infiltration in EAM mice}

As shown in Fig. 2A, significant inflammatory cellular infiltration was observed in the EAM mice, and 1, 25(OH)2 D3 ameliorated the extent of inflammatory infiltration. The pathological scores of heart sections in the EAM group were significantly elevated compared with those in the normal control group $(\mathrm{P}<0.01)$, and they were much lower in the 1 , $25(\mathrm{OH}) 2 \mathrm{D} 3$-treated EAM group compared with the vehicle -treated EAM group $(\mathrm{P}<0.05$; Fig. 2B). The ratio of $\mathrm{HW} / \mathrm{BW}$ was increased in the EAM group compared with the control group ( $\mathrm{P}<0.01)$, and it was much lower in the 1, 25(OH)2 D3 -treated EAM group compared with the vehicle -treated ones ( $\mathrm{P}<0.05$; Fig. $2 \mathrm{C})$.

\section{Administration of 1, 25(OH)2 D3 reduced myocardiocytes apoptosis in EAM mice}

To determine the effect of 1, 25(OH)2 D3 on myocardiocytes apoptosis, the EAM mice were treated with vehicle or $1,25(\mathrm{OH}) 2 \mathrm{D} 3$, and myocardiocytes apoptosis was assessed. Our results showed that, compared with vehicle treatment, the administration of $1,25(\mathrm{OH}) 2$ D3 markedly reduced EAM- induced myocardiocytes apoptotic responses as assessed by reduced TUNEL staining $(\mathrm{P}<0.01 ; \mathrm{Fig}$. $3 \mathrm{~A})$. In addition, we examined the protein expression of caspase- 3 and cleaved-caspase-3. In the EAM group, the expression of caspase- 3 and cleaved-caspase- 3 were increased compared with those in the control group $(\mathrm{P}<0.01)$. 


\section{Cellular Physiology Cell Physiol Biochem 2016;38:2219-2229

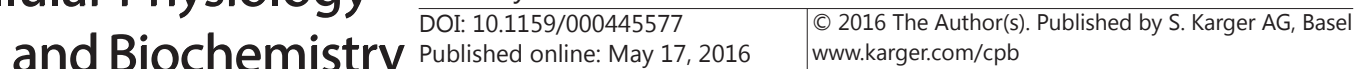

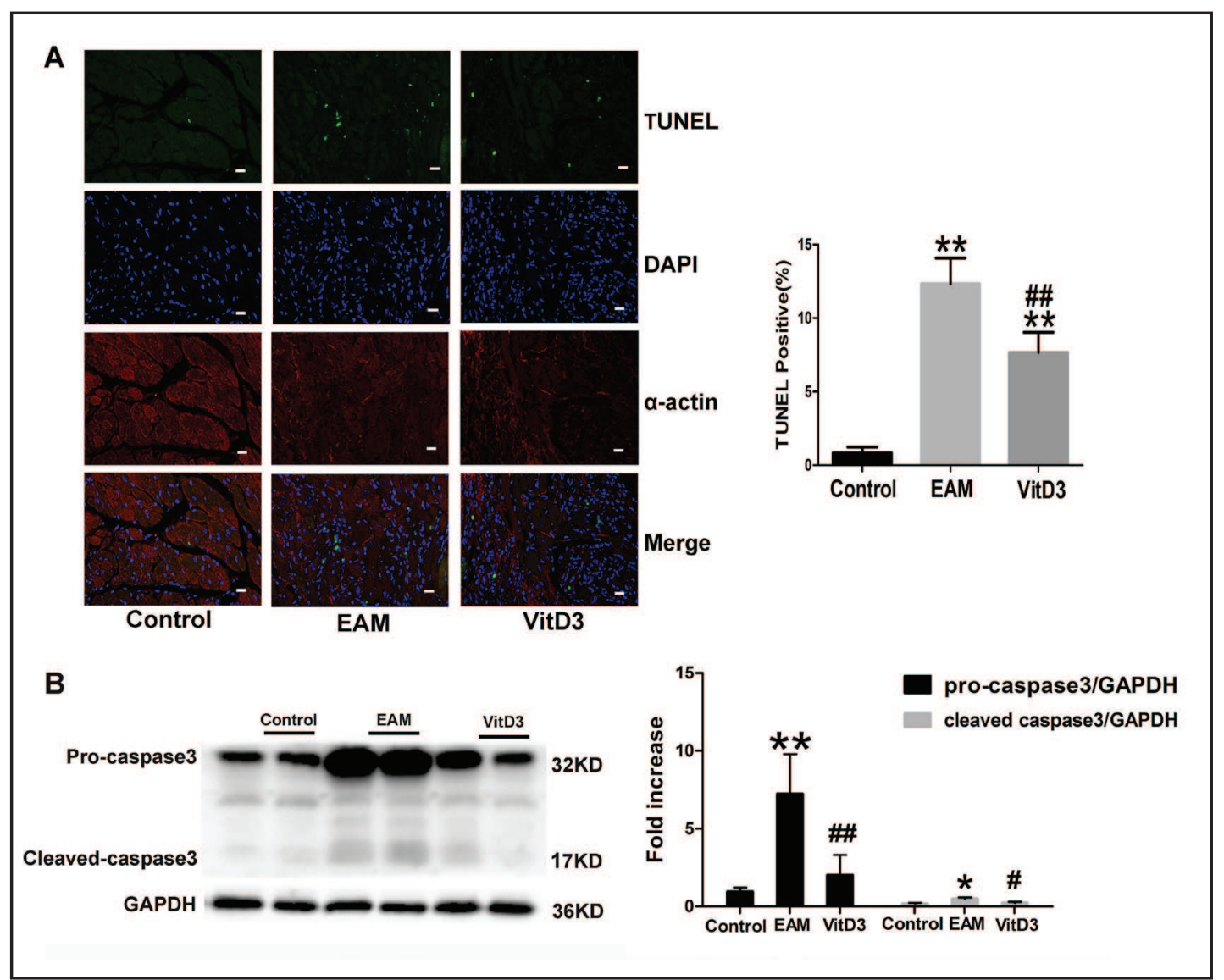

Fig. 3. 1, 25(OH) 2 D3 treatment reduced myocardiocytes apoptosis in EAM mice. (A) Myocardiocytes apoptosis was determined by TUNEL (green, apoptotic nuclei; blue, DAPI, total nuclei; red, $\alpha$-actin, cardiomyocytes), Scale bar $=50 \mu \mathrm{m}$. (B) Representative Western blot and quantitative analysis of pro-caspase-3, and cleaved-caspase- 3 . Values are expressed as the means \pm SEMs, $\mathrm{n}=6$ animals per group. ${ }^{*} \mathrm{P}<0.05$ or $* * \mathrm{P}<0.01$ vs. the control group; ${ }^{\mathrm{P}}<0.05$ or ${ }^{\# \#} \mathrm{P}<0.01$ vs. the EAM group.

1, 25(OH)2 D3 treatment decreased the expression of caspase-3 and cleaved-caspase-3 (P<0.01; Fig. 3B).

Overall, these results showed that 1,25(OH)2 D3 suppressed cardiomyocytes apoptosis in EAM mice.

Administration of 1, 25(OH)2 D3 influenced autophagy in EAM mice

In addition to apoptosis, we assessed the effect of 1, 25(OH)2 D3 on autophagy. As shown in Fig. 4A, transmission electron microscopy (TEM) revealed increased autophagosomes in the vehicle-treated EAM mouse hearts, while 1, 25(OH)2 D3 treatment reduced the number of autophagosomes. Due to their importance in autophagosome formation, we measured the expression of LC3-II (microtubule-associated protein 1 light chain 3-II), the expression of Beclin-1, and the expression of SQSTM1/p62. P62 is a marker of autophagy-mediated protein degradation, and its level is a marker of autophagic flux [24, 25]. As shown in Fig. 4B and 4C, Western blot analysis showed that the protein expression of Beclin-1 and LC3-II were significantly increased in the EAM hearts $(\mathrm{P}<0.05)$. The expression of p62 was not reduced and was even increased in the EAM group (Fig. 4D). Additionally, the LC3-II level was unchanged in chloroquine ( $\mathrm{CQ}$, lysosome inhibitor that prevents autophagosome-lysosome fusion)-treated EAM mice compared with vehicle-treated EAM mice (Fig. 4E). These results suggested that EAM induced autophagosome formation with abnormal autophagosome 


\section{Cellular Physiology Cell Physiol Biochem 2016;38:2219-2229

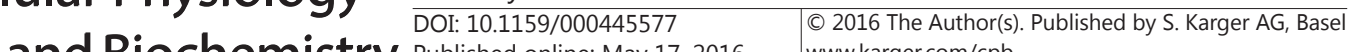 and Biochemistry Published online: May 17, 2016 www.karger.com/cpb}
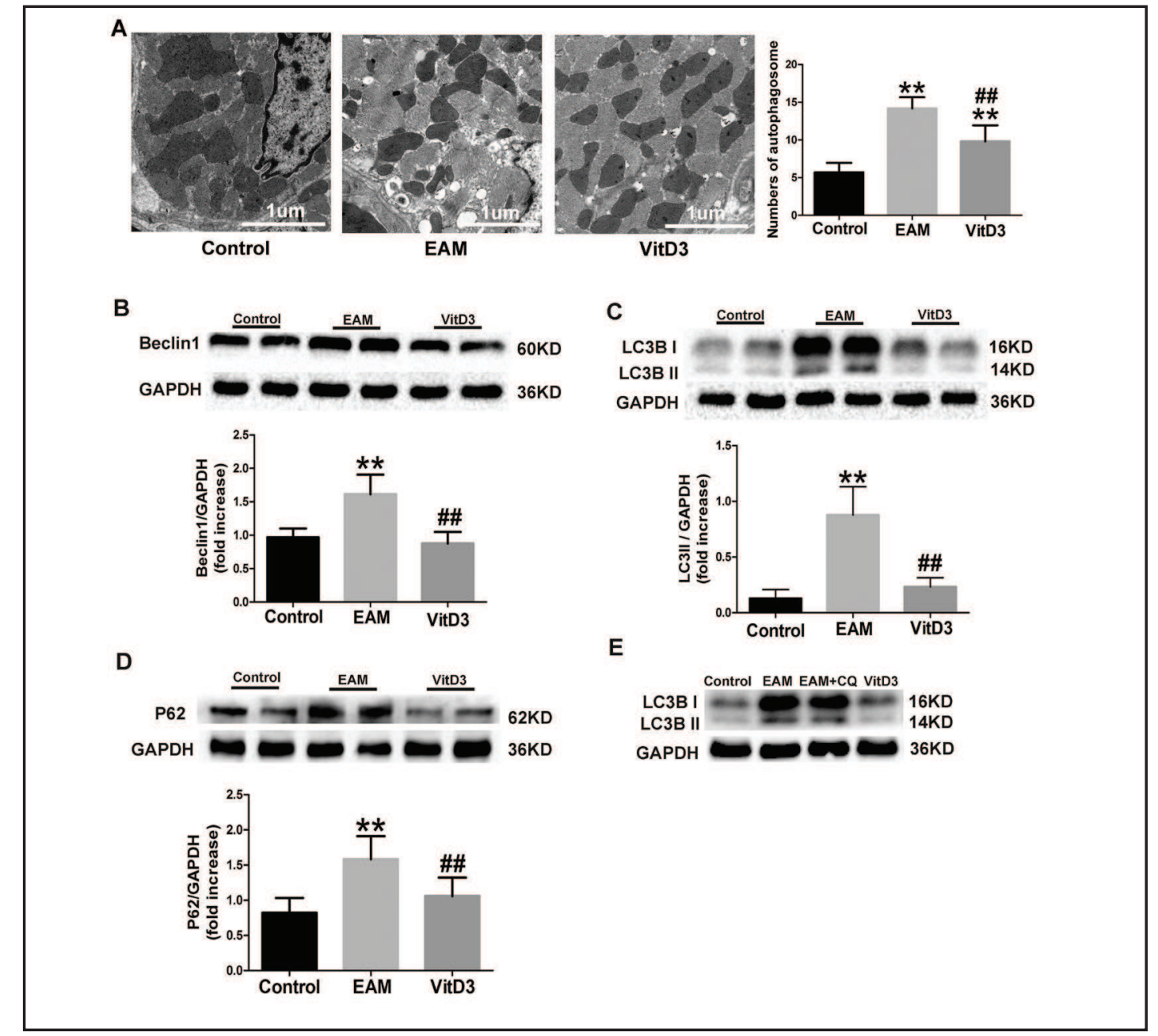

Fig. 4. 1, 25(OH) D3 treatment influenced autophagy in EAM mice. (A) Representative transmission electron microscopy images and the results of the statistical analysis of the numbers of autophagosomes from 20 fields ( $\mathrm{n}=3$ hearts per group). Representative Western blot and quantitative analysis of Beclin-1 (B), LC3-II (C), and p62 (D). An LC3 turnover assay was conducted in our subsequent experiment (E) and showed that the LC3-II levels remained unchanged in the chloroquine-treated $(2 \mathrm{mg} / \mathrm{Kg}$ intraperitoneally injected $2 \mathrm{~h}$ before sacrifice) EAM mice compared with the vehicle-treated EAM mice. Values are expressed as the means \pm SEMs, $\mathrm{n}=6$ hearts per group. ${ }^{*} \mathrm{P}<0.05$ or ${ }^{* *} \mathrm{P}<0.01$ vs. the control group; ${ }^{\#} \mathrm{P}<0.05$ or ${ }^{\# \#} \mathrm{P}<$ 0.01 vs. the EAM group.

clearance. Compared with the EAM group, 1, 25(OH)2 D3 treatment reduced the expression of Beclin-1, LC3-II, and p62 protein (Fig. 4B-D; P < 0.05). Taken together, these results suggested that 1, 25(OH)2 D3 modulated autophagy dysfunction in EAM mice.

\section{Discussion}

Myocarditis is an acute inflammatory disease of the heart, characterized by inflammatory cellular infiltrations. Studies have suggested that immune responses, inflammatory cytokines, oxidative stress, endoplasmic reticulum (ER) stress, and cell apoptosis are involved in the pathogenesis and development of EAM [26-28]. In this study, our data demonstrated that 1, 25(OH)2 D3 treatment can ameliorate EAM severity by reducing cardiac inflammatory infiltration and suppressing myocardial apoptosis. Fewer inflammatory cells in the cardiac 


\section{Cellular Physiology Cell Physiol Biochem 2016;38:2219-2229 \\ \begin{tabular}{ll|l} 
and Biochemistry $10.1159 / 000445577$ & $\begin{array}{l}\text { () 2016 The Author(s). Published by S. Karger AG, Basel } \\
\text { www.karger.com/cpb }\end{array}$ \\
\cline { 2 - 3 }
\end{tabular} \\ Hu et al.: 1, 25(OH)2 D3 on Autoimmune Myocarditis}

tissue of the 1, 25(OH)2 D3 group were observed compared with the EAM group. The pathological scores for the 1,25(OH)2 D3 treated EAM mice were lower than those for the vehicle treated EAM mice. 1, 25( $\mathrm{OH}) 2$ D3 treatment attenuated the activation of caspase-3. The TUNEL staining results showed that the number of apoptotic cells was reduced by 1 , 25(OH)2 D3 treatment. Echocardiographic results suggested that treatment with 1, 25(OH)2 D3 improved cardiac function. These data revealed an important role for 1, 25(OH)2 D3 in improving cardiac function accompanied with myocardiocytes apoptosis reduction.

Vitamin D has been extensively studied. In addition to bone metabolism and mineral ion homoeostasis, vitamin D participates in many biological processes. It can limit inflammation and inhibit cancer development and progression, and it has an anti-inflammatory effect on a variety of cell types, such as endothelial cells and immune cells [29-32]. 1, 25(OH)2 D3 can exert effects on T cells and B cells directly. It can inhibit Th1 cell development and enhance the Th2 cells development, reducing the production of proinflammatory cytokine [19]. What's more, it can induce B cells apoptosis, inhibiting plasma-cell differentiation and autoantibody production [19]. The possible effects of 1, 25(OH)2 D3 on lymphocytes and immunomodulatory may contribute to the improvement of cardiac function in EAM.

Vitamin D deficiency is prevalent in adults because of inadequate intake from food or decreased exposure to sunlight and is important in the pathology of many types of diseases. Low vitamin D levels have been associated with an increased risk for breast, colorectal, and prostate cancer [33,34], as well as autoimmune disorders and periodontal disease [35, 36]. In the cardiovascular system, epidemiological evidence suggests a correlation between low vitamin D status and a high incidence of cardiovascular diseases [37]. Vitamin D deficiency is associated with elevated blood pressure, electrolyte imbalances, renin-angiotensin system (RAS) activation, ventricular hypertrophy and heart failure [37, 38].

Autophagy, a lysosome-mediated catabolic pathway, has an important role in maintaining cellular homeostasis and occurs in almost all eukaryotic cells [39]. Defects in autophagy may be associated with cancer, neurodegenerative diseases, and aging [8]. Autophagy is considered to have a pro-survival role because the deletion of some critical genes for autophagy accelerates rather than inhibits cell death [40-42]. However, some evidences showed that unbridled autophagy may result in cell death by degrading some critical proteins or excessive self-digestion [43-46]. Impaired autophagosome clearance may lead to ischemia/reperfusion-induced cardiomyocyte cell death [47]. Wong et al. [48] reported that CVB3 infection induced the activation of autophagy machinery in the host, which could enhance viral replication. Yuan et al. [49] showed that autophagy contributed to IL-17-induced autoantibody production in plasma cells in EAM and inhibiting autophagy with 3-MA (autophagy inhibitor) alleviated the effect of rIL-17. In this study, our results showed that increased autophagosome formation was observed in EAM mice, as evidenced by the increased number of autophagosomes, upregulation of Beclin-1and LC3-II. An impaired autophagic flux was observed in the EAM mice, as the expression of LC3-II was increased in the EAM mice and the LC3-II level remained unchanged in the chloroquine-treated EAM mice compared with the vehicle-treated EAM mice, the expression of protein P62 was not reduced and was even increased in EAM mice. These results suggested that autophagy dysfunction existed in EAM, as evidenced by an increase in autophagosome formation and abnormal autophagosome degradation by lysosomes.

A growing number of studies have suggested that vitamin D could regulate autophagy at different levels. It can induce autophagy to maintain cell viability, reduce cell apoptosis, and attenuate the severity of disease. Meanwhile, it plays essential roles in regulating autophagy to avoid autophagy dysfunction-mediated cell death. Yao et al. [50] showed that vitamin D inhibited autophagy dysfunction-mediated cell death and improved cardiac function. In the present study, we showed that 1,25(OH)2 D3 treatment improved autophagy dysfunction since the reduction of Beclin-1, LC3-II and p62 protein expression were observed in the 1 , 25(OH)2 D3 treated EAM mice.

In summary, the present study demonstrated that $1,25(\mathrm{OH}) 2 \mathrm{D} 3$ is capable of improving cardiac function by inhibiting cardiac inflammatory infiltration, reducing myocardiocytes 


\section{Cellular Physiology Cell Physiol Biochem 2016;38:2219-2229 \begin{tabular}{l|l|l}
\hline DOI: 10.1159/000445577 & (c) 2016 The Author(s). Published by S. Karger AG, Basel
\end{tabular} and Biochemistry Published online: May 17, 2016 www.karger.com/cpb}

Hu et al.: 1, 25(OH)2 D3 on Autoimmune Myocarditis

apoptosis, and autophagy modulation. 1, 25(OH)2 D3 treatment may therefore be a promising therapeutic strategy for the clinical treatment of myocarditis. However, since excessive vitamin D could lead to calcification, further studies are needed to determine the proper dosages and to evaluate the clinical usefulness and effectiveness of treatment for myocarditis in humans.

\section{Acknowledgments}

This project was supported by grants from the National Natural Science Foundation of China (81170205 and 81370405).

\section{Disclosure Statement}

The authors declare that they have no interests that could influence the publication of this paper.

\section{References}

1 Leuschner F, Katus HA, Kaya Z: Autoimmune myocarditis: past, present and future. J Autoimmun 2009;33:282-289.

2 Reddy J, Massilamany C, Buskiewicz I, Huber SA: Autoimmunity in viral myocarditis. Curr Opin Rheumatol 2013;25:502-508.

3 Caforio AL, Marcolongo R, Jahns R, Fu M, Felix SB, Iliceto S: Immune-mediated and autoimmune myocarditis: clinical presentation, diagnosis and management. Heart Fail Rev 2013;18:715-732.

4 Neu N, Beisel KW, Traystman MD, Rose NR, Craig SW: Autoantibodies specific for the cardiac myosin isoform are found in mice susceptible to Coxsackievirus B3-induced myocarditis. J Immunol 1987; 138:2488-2492.

5 Hirakawa H, Zempo H, Ogawa M, Watanabe R, Suzuki J, Akazawa H, Komuro I, Isobe M: A DPP-4 inhibitor suppresses fibrosis and inflammation on experimental autoimmune myocarditis in mice. PLoS One 2015;10:e0119360.

6 Weidberg H, Shpilka T, Shvets E, Abada A, Shimron F, Elazar Z: LC3 and GATE-16 N termini mediate membrane fusion processes required for autophagosome biogenesis. Dev Cell 2011;20:444-454.

$7 \quad$ Klionsky DJ, Emr SD: Autophagy as a regulated pathway of cellular degradation. Science 2000;290:17171721.

8 Levine B, Mizushima N, Virgin HW: Autophagy in immunity and inflammation. Nature 2011;469:323-335.

9 Levine B, Kroemer G: Autophagy in the pathogenesis of disease. Cell 2008;132:27-42.

10 Wang RC, Levine B: Autophagy in cellular growth control. FEBS Lett 2010;584:1417-1426.

11 Grenier D, Morin MP, Fournier-Larente J, Chen H: Vitamin D inhibits the growth of and virulence factor gene expression by Porphyromonas gingivalis and blocks activation of the nuclear factor kappa B transcription factor in monocytes. J Periodontal Res DOI: 10.1111/jre.12315.

12 Chang Se, Li Z, Gao L, Yang Y, Song T, Tong D, Huang C: miR-145 mediates the antiproliferative and gene regulatory effects of vitamin D3 by directly targeting E2F3 in gastric cancer cells. Oncotarget 2015;6:76757685.

13 Zhang Y, Guo Q Zhang Z, Bai N, Liu Z, Xiong M, Wei Y, Xiang R, Tan X: VDR status arbitrates the prometastatic effects of tumor-associated macrophages. Mol Cancer Res 2014;12:1181-1191.

14 Ferreira GB, Vanherwegen AS, Eelen G, Gutierrez AC, Van Lommel L, Marchal K, Verlinden L, Verstuyf A, Nogueira T, Georgiadou M, Schuit F, Eizirik DL, Gysemans C, Carmeliet P, Overbergh L, Mathieu C: Vitamin D3 induces tolerance in human dendritic cells by activation of intracellular metabolic pathways. Cell Rep 2015;10:711-725.

15 Feldman D, Krishnan AV, Swami S, Giovannucci E, Feldman BJ: The role of vitamin D in reducing cancer risk and progression. Nat Rev Cancer 2014;14:342-357. 


\section{Cellular Physiology Cell Physiol Biochem 2016;38:2219-2229 \begin{tabular}{ll|l} 
DOI: 10.1159/000445577 & $\begin{array}{l}\text { @ 2016 The Author(s). Published by S. Karger AG, Basel } \\
\text { www.karger.com/cpb }\end{array}$ \\
\hline
\end{tabular}}

Hu et al.: 1, 25(OH)2 D3 on Autoimmune Myocarditis

16 Wang W, Li G, He X, Gao J, Wang R, Wang Y, Zhao W: Serum 25-hydroxyvitamin D levels and prognosis in hematological malignancies: a systematic review and meta-analysis. Cell Physiol Biochem 2015;35:19992005.

17 Zhang H, Zhang H, Wen X, Zhang Y, Wei X, Liu T: Vitamin D Deficiency and Increased Risk of Bladder Carcinoma: A Meta-Analysis. Cell Physiol Biochem 2015;37:1686-1692.

18 Zhang L, Wang S, Che X, Li X: Vitamin D and lung cancer risk: a comprehensive review and meta-analysis. Cell Physiol Biochem 2015;36:299-305.

19 Adorini L, Penna G: Control of autoimmune diseases by the vitamin D endocrine system. Nat Clin Pract Rheumatol 2008;4:404-412.

20 Neu N, Klieber R, Fruhwirth M, Berger P: Cardiac myosin-induced myocarditis as a model of postinfectious autoimmunity. Eur Heart J 1991;12:117-120.

21 Nishio R, Matsumori A, Shioi T, Ishida H, Sasayama S: Treatment of experimental viral myocarditis with interleukin-10. Circulation 1999;100:1102-1108.

22 Yuan J, Yu M, Li HH, Long Q, Liang W, Wen S, Wang M, Guo HP, Cheng X, Liao YH: Autophagy contributes to IL-17-induced plasma cell differentiation in experimental autoimmune myocarditis. Int Immunopharmacol 2014;18:98-105.

23 Ezaki J, Matsumoto N, Takeda-Ezaki M, Komatsu M, Takahashi K, Hiraoka Y, Taka H, Fujimura T, Takehana K, Yoshida M, Iwata J, Tanida I, Furuya N, Zheng DM, Tada N, Tanaka K, Kominami E, Ueno T: Liver autophagy contributes to the maintenance of blood glucose and amino acid levels. Autophagy 2011;7:727-736.

24 Zhou KL, Zhang YH, Lin DS, Tao XY, Xu HZ: Effects of calcitriol on random skin flap survival in rats. Sci Rep 2016;6:18945.

25 Wong J, Zhang J, Si X, Gao G, Mao I, McManus BM, Luo H: Autophagosome supports coxsackievirus B3 replication in host cells. J Virol 2008;82:9143-9153.

26 Li WM, Liu W, Gao C, Zhou BG: Immunoregulatory effects of atorvastatin on experimental autoimmune myocarditis in Lewis rats. Immunol Cell Biol 2006;84:274-280.

27 Liu X, Li B, Wang W, Zhang C, Zhang M, Zhang Y, Xia Y, Dong Z, Guo Y, An F: Effects of HMG-CoA reductase inhibitor on experimental autoimmune myocarditis. Cardiovasc Drugs Ther 2012;26:121-130.

28 Shimazaki H, Watanabe K, Veeraveedu PT, Harima M, Thandavarayan RA, Arozal W, Tachikawa H, Kodama M, Aizawa Y: The antioxidant edaravone attenuates ER-stress-mediated cardiac apoptosis and dysfunction in rats with autoimmune myocarditis. Free Radic Res 2010;44:1082-1090.

29 Equils O, Naiki Y, Shapiro AM, Michelsen K, Lu D, Adams J, Jordan S: 1,25-Dihydroxyvitamin D inhibits lipopolysaccharide-induced immune activation in human endothelial cells. Clin Exp Immunol 2006;143:5864.

30 Martinesi M, Bruni S, Stio M, Treves C: 1,25-Dihydroxyvitamin D3 inhibits tumor necrosis factor-alphainduced adhesion molecule expression in endothelial cells. Cell Biol Int 2006;30:365-375.

31 Harishankar M, Anbalagan S, Selvaraj P: Effect of vitamin D on chemokine levels and regulatory T-cells in pulmonary tuberculosis. Int Immunopharmacol 2016;34:86-91.

32 Kariuki SN, Blischak JD, Nakagome S, Witonsky DB, Di Rienzo A: Patterns of Transcriptional Response to 1,25-dihydroxyvitamin D3 and Bacterial Lipopolysaccharide in Primary Human Monocytes. G3 (Bethesda) DOI:10.1534/g3.116.028712.

33 Bilinski K, Boyages J: Association between 25-hydroxyvitamin D concentration and breast cancer risk in an Australian population: an observational case-control study. Breast Cancer Res Treat 2013;137:599-607.

34 Hibler EA, Molmenti CL, Lance P, Jurutka PW, Jacobs ET: Associations between circulating 1,25(OH)(2)D concentration and odds of metachronous colorectal adenoma. Cancer Causes Control 2014;25:809-817.

35 Adorini L, Penna G: Control of autoimmune diseases by the vitamin D endocrine system. Nat Clin Pract Rheumatol 2008;4:404-412.

36 Wu S, Sun J: Vitamin D, vitamin D receptor, and macroautophagy in inflammation and infection. Discov Med 2011;11:325-335.

37 Al Mheid I, Patel RS, Tangpricha V, Quyyumi AA: Vitamin D and cardiovascular disease: is the evidence solid? Eur Heart J 2013;34:3691-3698.

38 Motiwala SR, Wang TJ: Vitamin D and cardiovascular risk. Curr Hypertens Rep 2012;14:209-218.

39 Reggiori F, Klionsky DJ: Autophagy in the eukaryotic cell. Eukaryot Cell 2002;1:11-21. 


\section{Cellular Physiology \\ Cell Physiol Biochem 2016;38:2219-2229 \\ \begin{tabular}{l|l}
\hline DOI: $10.1159 / 000445577$ & C 2016 The Author(s). Published by S. Karger AG, Basel
\end{tabular} and Biochemistry Published online: May 17, 2016 www.karger.com/cpb}

Hu et al.: 1, 25(OH)2 D3 on Autoimmune Myocarditis

40 Kroemer G, Galluzzi L, Vandenabeele P, Abrams J, Alnemri ES, Baehrecke EH, Blagosklonny MV, El-Deiry WS, Golstein P, Green DR, Hengartner M, Knight RA, Kumar S, Lipton SA, Malorni W, Nunez G, Peter ME, Tschopp J, Yuan J, Piacentini M, Zhivotovsky B, Melino G, Nomenclature Committee on Cell Death: Classification of cell death: recommendations of the Nomenclature Committee on Cell Death 2009. Cell Death Differ 2009;16:3-11.

41 Galluzzi L, Maiuri MC, Vitale I, Zischka H, Castedo M, Zitvogel L, Kroemer G: Cell death modalities: classification and pathophysiological implications. Cell Death Differ 2007;14:1237-1243.

42 Nakai A, Yamaguchi O, Takeda T, Higuchi Y, Hikoso S, Taniike M, Omiya S, Mizote I, Matsumura Y, Asahi M, Nishida K, Hori M, Mizushima N, Otsu K: The role of autophagy in cardiomyocytes in the basal state and in response to hemodynamic stress. Nat Med 2007;13:619-624.

43 Gustafsson AB, Gottlieb RA: Recycle or Die: The Role of Autophagy in Cardioprotection. J Mol Cell Cardiol 2008;44:654-661.

44 Hotchkiss RS, Strasser A, McDunn JE, Swanson PE: Cell death. N Engl J Med 2009;361:1570-1583.

45 Klionsky DJ: Autophagy: from phenomenology to molecular understanding in less than a decade. Nat Rev Mol Cell Biol 2007;8:931-937.

46 Takasu O, Gaut JP, Watanabe E, To K, Fagley RE, Sato B, Jarman S, Efimov IR, Janks DL, Srivastava A, Bhayani SB, Drewry A, Swanson PE, Hotchkiss RS: Mechanisms of cardiac and renal dysfunction in patients dying of sepsis. Am J Respir Crit Care Med 2013;187:509-517.

47 Ma X, Liu H, Foyil SR, Godar RJ, Weinheimer CJ, Hill JA, Diwan A: Impaired autophagosome clearance contributes to cardiomyocyte death in ischemia/reperfusion injury. Circulation 2012;125:3170-3181.

48 Wong J, Zhang J, Si X, Gao G, Mao I, McManus BM, Luo H: Autophagosome supports coxsackievirus B3 replication in host cells. J Virol 2008;82:9143-9153.

49 Yuan J, Yu M, Li HH, Long Q, Liang W, Wen S, Wang M, Guo HP, Cheng X, Liao YH: Autophagy contributes to IL-17-induced plasma cell differentiation in experimental autoimmune myocarditis. Int Immunopharmacol 2014;18:98-105.

50 Yao T, Ying X, Zhao Y, Yuan A, He Q Tong H, Ding S, Liu J, Peng X, Gao E, Pu J, He B: Vitamin D receptor activation protects against myocardial reperfusion injury through inhibition of apoptosis and modulation of autophagy. Antioxid Redox Signal 2015;22:633-650. 